\title{
Improving Pallet Mover Safety in the Manufacturing Industry: A Bow-Tie Analysis of Accident Scenarios
}

\author{
Karolien van Nunen ${ }^{1,2}, * \mathbb{D}$, Paul Swuste ${ }^{2,3}$, Genserik Reniers ${ }^{2,3}$, Nicola Paltrinieri ${ }^{4}$, \\ Olga Aneziris ${ }^{5}$ and Koen Ponnet ${ }^{6}$ \\ 1 Research Chair Vandeputte, Law Enforcement, Faculty of Law, University of Antwerp, \\ 2000 Antwerp, Belgium \\ 2 Antwerp Research Group on Safety and Security (ARGoSS), Engineering Management, \\ Faculty of Applied Economics, University of Antwerp, 2000 Antwerp, Belgium; \\ P.H.J.J.Swuste@tudelft.nl (P.S.); G.L.L.M.E.Reniers@tudelft.nl (G.R.) \\ 3 Safety and Security Science, Faculty of Technology, Policy and Management, \\ Delft University of Technology, 2628 CD Delft, The Netherlands \\ 4 Department of Mechanical and Industrial Engineering, Norwegian University of Science and \\ Technology—NTNU, 7491 Trondheim, Norway; nicola.paltrinieri@ntnu.no \\ 5 National Centre for Scientific Research “Demokritos", 15310 Agia Paraskevi, Greece; \\ olga@ipta.demokritos.gr \\ 6 Media, ICT \& Interpersonal Relations in Organisations \& Society (MIOS), \\ Faculty of Political and Social Sciences, University of Antwerp, 2000 Antwerp, Belgium; \\ koen.ponnet@uantwerpen.be \\ * Correspondence: karolien.vannunen@uantwerpen.be; Tel.: +31-498-522-100
}

Received: 22 August 2018; Accepted: 9 October 2018; Published: 12 October 2018

\begin{abstract}
A Belgian manufacturing company uses pallet movers for internal transport. Despite the company's efforts to improve occupational safety, accidents with pallet movers remain noteworthy. In order to control occupational accidents, it is crucial to have a clear view of the potential accident scenarios that are present in a company. The bow-tie method is a way to capture and visualize these accident processes in an integrative way. Included in the bow-tie are safety barriers (both technical as organizational and human) and management delivery systems that can intervene in these accident processes. Once bow-ties are composed, they are an excellent point of departure to assign indicators to the safety barriers and management delivery systems in order to control (i.e., prevent or mitigate) accident scenarios. Two types of indicators can be distinguished. Firstly, there are general indicators that are assigned to management delivery systems interrupting multiple accident scenarios, which can yield a higher safety gain (as they intervene in multiple accident scenarios). Secondly, there are scenario-specific indicators targeting one specific accident scenario, which can be valuable as they target a specific problem in the company. For the development of the bow-ties, a multi-method design with the inclusion of different data sources was used, leading to a comprehensive overview. This makes the bow-tie analysis of internal transport with pallet movers transferable to other settings where pallet movers are used for internal transport.
\end{abstract}

Keywords: manufacturing industry; bow-tie analysis; pallet mover accidents; accident analysis; safety barriers

\section{Introduction of the Study}

Internal transport represents a well-known occupational hazard in many modern industrial environments. Pallet movers (synonyms for 'pallet mover' are pallet jack, walkie-rider, pallet truck, transpallet) are used for internal transport in several industries, and these machines are easy to operate, 
compared to, for example, forklift trucks. However, pallet movers are inherently dangerous machines. They often operate close to pedestrian workers and, charged with a load, their total mass can be well above two tons. Often, their load is not secured to the machine, leading to instability when gravity gets a grip of the load.

The company under investigation in this study is a manufacturing plant located in Belgium, which is part of an American multinational, producing consumer products all over the world. Pallet movers are used frequently for internal transport. Like many major American companies, this company also pays a lot of attention to the safety of their employees. The company uses the so-called $6 \mathrm{~W}-2 \mathrm{H}$ and why-why techniques to analyze its recordable accidents without or with lost work time. The $6 \mathrm{~W}-2 \mathrm{H}$ problem analysis produces a description of the context of accidents (what, where, which, when, who, to whom, how, how much). The why-why analysis is performed to get to the so-called root causes of accidents and is based on mapping of what happened during the accident process and why this happened. Countermeasures are formulated based on the results of these accident analyzes. The entire accident analysis is the responsibility of the supervisors, but are hereby supported by the Health and Safety (HSEQ) staff.

According to figures provided by the European safety manager of the abovementioned multinational, the $6 \mathrm{~W}-2 \mathrm{H}$ and why-why techniques did not help in reducing occupational accidents substantially. As an alternative, a bow-tie analysis is proposed, providing a detailed and comprehensive insight into potential accident scenarios, including possible safety barriers (both technical and non-technical) and management delivery systems which can prevent or mitigate the accident processes. In Section 4, the choice for the bow-tie method is supported.

To test the bow-tie analysis, a pilot project was formulated, focussing on accidents during internal transport with pallet movers. Accidents with pallet movers represent a significant share of the total number of accidents. In the years 2015 and 2016, about ten percent of all recordable accidents with lost work time that occurred at the European plants of the multinational involved a pallet mover.

The research question of this study is 'Which accident scenarios are possible during internal transport with pallet movers and which safety barriers (both technical as organizational and human) and management delivery systems can influence (i.e., prevent or mitigate) these accident scenarios?'.

\section{Background of the Plant under Investigation}

At the Belgian plant, approximately 300 people are employed. Two out of three employees are permanent ('own company employees') and one out of three is a contractor.

The production process is manifested on several floors. The upper floors are responsible for supplying raw materials, the production of intermediate products, and supplying these intermediate products to lower floors, where product finishing and packing take place. The ground floor has production lines for finishing the products and packing lines. These lines are implanted in an existing space which was initially not designed for that purpose.

The entire plant is characterized by a lot of load manipulation, which means that products are stocked in many temporary buffers. For example, on the ground floor, the packing materials are transported from the warehouse to a first large buffer (by a forklift truck), followed by transportation from the first large buffer to a second smaller buffer (by a pallet mover), and from the second smaller buffer to a buffer in front of the production or packing line (by a pallet mover).

The transportation routes of forklift trucks are separated from transportation routes of pallet movers, leading to (almost) no possible contact between the two types of internal transport.

Figure 1 shows two types of pallet movers being used at the plant: Standard electrical pallet movers and electrical stackers which can lift loads to approximately $1.8 \mathrm{~m}$. Pallet movers can transport a load of 1.2 to 2 tons, have a driving speed up to $6 \mathrm{~km} / \mathrm{h}$ and a standard emergency stop. Maintenance and repair of pallet movers are performed by the company itself on a regular basis, while inspections are performed by an external company every three months. 
Approximately $75 \%$ of the operators handling pallet movers are provided by one steady contractor company. The contractor staff is characterized by a frequent rotation.

Figure 2 shows the most frequent loads transported at the plant. Finished products are not transported with pallet movers, only raw materials, intermediate products, packing material, and off-quality products.

During the period from 2015 to 2016, eight recordable accidents occurred at the Belgian location. In three of these accidents, a pallet mover was involved. Two of these pallet mover accidents happened with a contractor employee, and one with a company employee.

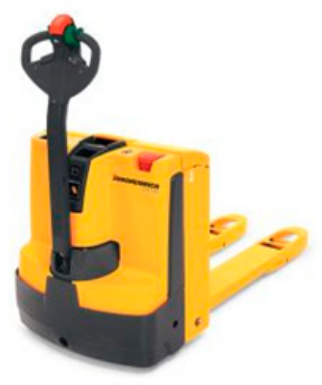

(a)

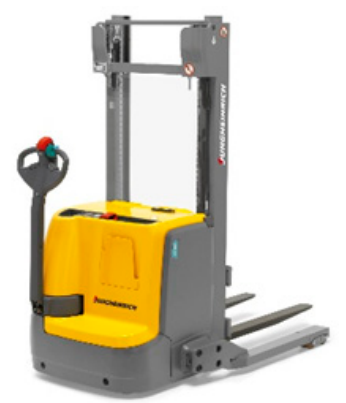

(b)

Figure 1. The types of pallet movers-(a): standard pallet mover and (b): stacker.

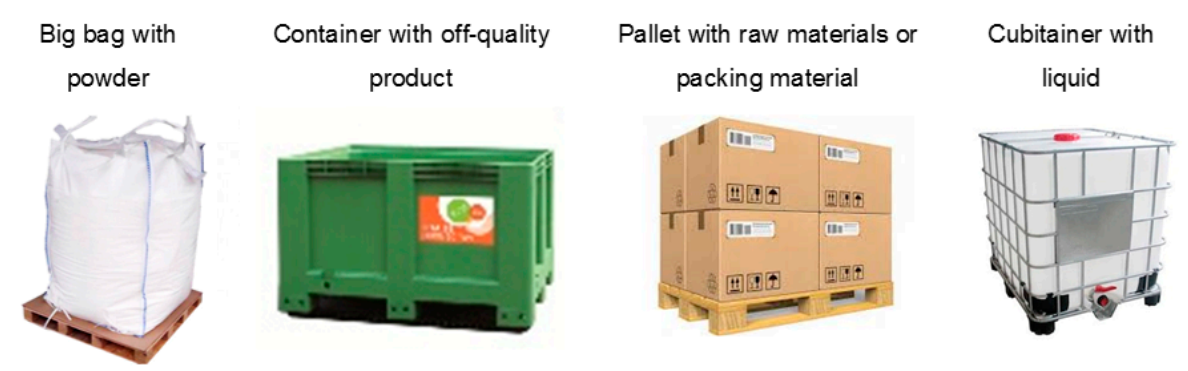

Figure 2. The most frequent loads transported with pallet movers.

\section{Research Methodology}

To compose the bow-ties of accidents with pallet movers, a multi-method design was used.

A literature search was conducted using electronic databases of the library of the Delft University of Technology, the British Health and Safety Executive (HSE), the American Occupational safety and Health Administration (OSHA), and the American National Institute for Occupational Safety and Health (NIOSH). Search terms were the following: 'pallet mover', 'pallet jack', 'walkie-rider', 'pallet truck, 'transpallet', and 'accident'. Safety related articles on pallet movers were rather scarce in the literature. Therefore, articles on forklift truck accidents (using the search term 'forklift') were also included in the literature study, for as far as the accident processes had similarities with the ones of pallet movers.

Belgian and Dutch national data on pallet mover accidents were requested. For Belgium, data on pallet mover accidents are obtained from Fedris, the Belgian federal agency for occupational risks. For The Netherlands, Storybuilder is used, which is a software tool developed for the Dutch Ministry of Social Affairs and Employment [1]. Both agencies have provided data on accidents reported to and investigated by the labor inspectorate. In both databases, the type of equipment involved in the accidents can be selected. This equipment classification is based on the classification by ESAW (European Statistics on Accidents at Work). Pallet movers fall under the code 11.04 ('mobile handling devices, handling trucks (powered or not)—barrows, pallet trucks, etc.'). It should be noted that the data obtained does not only cover accidents with pallet movers, but also other equipment falling under the same code. Hence, national numbers of pallet mover accidents cannot be given. However, 
the databases also contain information on types of accident scenarios, root causes, and failing safety barriers. The latter qualitative information was used to complement the development of the bow-ties.

Documents and data concerning pallet mover safety available at the Belgian plant (and by extension at all European plants if available) were analyzed: The material of the pallet mover training (presentation, syllabus), an observation checklist used to evaluate the use of pallet movers (HSEQ staff and supervisors use this checklist to evaluate the behavior of operators during pallet mover use), the minutes of monthly safety meetings, a pallet mover maintenance checklist, the most recent pallet mover inspection overview, a checklist for interims regarding pallet mover use, and the safety notifications regarding pallet movers in the incident registration system. During 2015-2016, 127 safety notifications regarding pallet movers were available at the Belgian plant comprising information on accidents $(n=9)$, near-misses $(n=9)$, unsafe conditions $(n=93)$, and positive feedback to the operators $(n=16)$. All available accident analyzes (the $6 \mathrm{~W}-2 \mathrm{H}$ and why-why techniques) performed after a recordable accident with a pallet mover were also taken into account. In Appendix A, an example of such a recordable accident is given, containing a short description of the accident and the actions taken in response to the accident.

At the Belgian plant, observations were being held at the workplaces of the pallet mover operators. A personal introduction of the researchers and the purpose of the study were given before the observations, and an introduction was given to the contractors during their daily team meetings. Observations were complemented with interviews with operators $(n=25)$, team leaders $(n=5)$, the HSEQ staff $(n=3)$, and management $(n=2)$. Interviews with operators and team leaders were performed on-the-job and took approximately fifteen minutes per person. The following aspects were addressed during the interviews:

- A job description of their tasks involving a pallet mover

- Problems and obstacles encountered during the use of pallet movers

- Facilitating aspects regarding the use of pallet movers

- Accidents, near-misses, or unsafe conditions with pallet movers

- Accidents that are most likely to occur with pallet movers

- Suggestions for improvement regarding the use of pallet movers

- Additional questions based on the observations

Interviews with the HSEQ staff and management were performed in a meeting room and took approximately one hour per person, discussing topics as the safety management system and findings during the fieldwork. The staff of the external company that provides the training of the pallet mover operators was also interviewed.

\section{The Bow-Tie Model}

The safety metaphor used in this study is the so-called bow-tie (Figure 3). The bow-tie model originates from the engineering domain and combines a hazard and safety barrier concept, dating as far back as DeBlois (1926), Gibson (1961) and Haddon (1963), together with a scenario concept, known from the Swiss cheese model of Reason (1997) [2-8]. A bow-tie model is comprised of a fault tree (the left-hand side of the model), which represents the risk factors of a failure, and an event tree (the right-hand side of the model), which represents the consequences of a failure [9].

The bow-tie metaphor illustrates an accident process, starting with a hazard on the left-hand side. A hazard (or energy) is a source or a condition with the potential for causing harm. Various accident scenarios, pictured as left-right arrows, can migrate to the center point of the metaphor, the central event. This central event represents a state where the hazard (energy) has become uncontrollable and, thus, becomes an undesirable event with a potential for harm or damage. The central event proceeds the consequences at the right-hand side of the metaphor, such as causing harm to people or damage to assets or environment. 
The strength of the metaphor is its relationship between accident scenarios, technical safety barriers, non-technical safety barriers, and management delivery systems. A scenario is a sequence of events and conditions necessary for an accident to occur. Looking at the scenarios, two types of events can be distinguished. There are pre-event accident scenarios presented at the left-hand side of the central event (leading to the central event), and there are post-event accident scenarios depicted at the right-hand side of the central event (leading to the consequences). The technical safety barriers, represented as the black boxes in the scenarios, are technical entities that can interrupt the accident scenario. An example of a technical safety barrier is an emergency stop on a pallet mover. The non-technical (or organizational and human) safety barriers are represented as the white boxes in the scenarios, being non-technical entities that can interrupt the accident scenario. An example of a non-technical safety barrier is the removal of leaking cubitainers (which interrupts the pre-event accident scenario of losing control over the pallet mover due to leaked products on the floor). The upwards arrows in Figure 3 represent the influence of management delivery systems. Management delivery systems influence the quality (in terms of reliability and availability) of the technical and non-technical safety barriers. For example, maintenance of the emergency stop on the pallet mover does not interrupt the accident scenario in a direct way, but is a management delivery system influencing the reliability of the technical safety barrier 'emergency stop on pallet mover'. Another example of a management delivery system is the training of pallet mover operators on removing leaking cubitainers, which influences the reliability of the non-technical safety barrier 'removal of leaking cubitainers'.

There are two types of safety barriers that can be distinguished. There are safety barriers to prevent the occurrence of the central event, which are presented in the pre-event accident scenarios, and there are safety barriers to control or to mitigate the consequences, which are presented in the post-event accident scenarios.

The bow-tie model has a hidden time factor. Less than adequate safety barriers or management delivery systems can be manifested over a long period of time. If a hazard becomes uncontrollable and reaches the central event, scenarios reaching their consequences will usually unroll very quickly. Pre-event accident scenarios may take days, week, months, or even longer, while post-event accident scenarios develop in hours, minutes, or even shorter.

After bow-ties are developed, the next step is to assign indicators to the safety barriers and the management delivery systems [10]. Indicators are able to visualize possibilities for improvement, to indicate safety improvement or safety decline over time, and create benchmarking (e.g., between different plants). Once the indicators are developed, targets and limits should be assigned to every indicator (what is acceptable or unacceptable as a result or for instance tolerable with leeway for improvement). Additionally, responsibilities have to be set up in order to achieve goals and to define actions when targets are not met. According to the needs of the company, indicators can be prioritized (which indicators are for instance more important or more feasible to implement).

Traditionally, the scope of accident and incident investigations, whether performed internally or externally, is usually limited to investigating the immediate causes and decision making processes related to the accident sequence. Important factors contributing to the accident are hereby often overlooked. However, since the method used to analyze incident data and accident information influences the proposed prevention measures, it should be of no surprise that those investigations don not directly guide one towards the most effective improvements and solutions. On the other extreme, methods and models to investigate the socio-technical system, such as those proposed by Rasmussen ('drift to danger' model) [11], Leveson (the STAMP method) [12] or Hollnagel (the FRAM method) [13], are often too general for the application intention, and this way surpass their goal. The bow-tie method as employed in this research finds a way between both situations, and thoroughly investigates a (possible) accident without being too high-level.

The majority of accident modeling techniques has been designed to address process safety. However, most of these models tend to be also applicable to the field of occupational safety [14]. The same applies for the bow-tie model, which has entered the field of occupational safety through 
the European Workgroup for development of the Occupational Risk Model (WORM), which started with the aim of decreasing the occupational accident rate in the Netherlands by $10-15 \%[14,15]$. The value of this model lies mainly in its suitability for qualitative analysis. In addition, bow-ties have been proposed for quantifying occupational risk in the framework of the WORM research project. An initial [16] and a more general form of the model have been presented in Reference [17]. Bowties for quantifying occupational risk have been presented in the following cases: Falls from heights [18], falling objects [19], contact with moving parts of machines [20], activities near moving vehicles [21], fires [22] and hazardous substances [23].

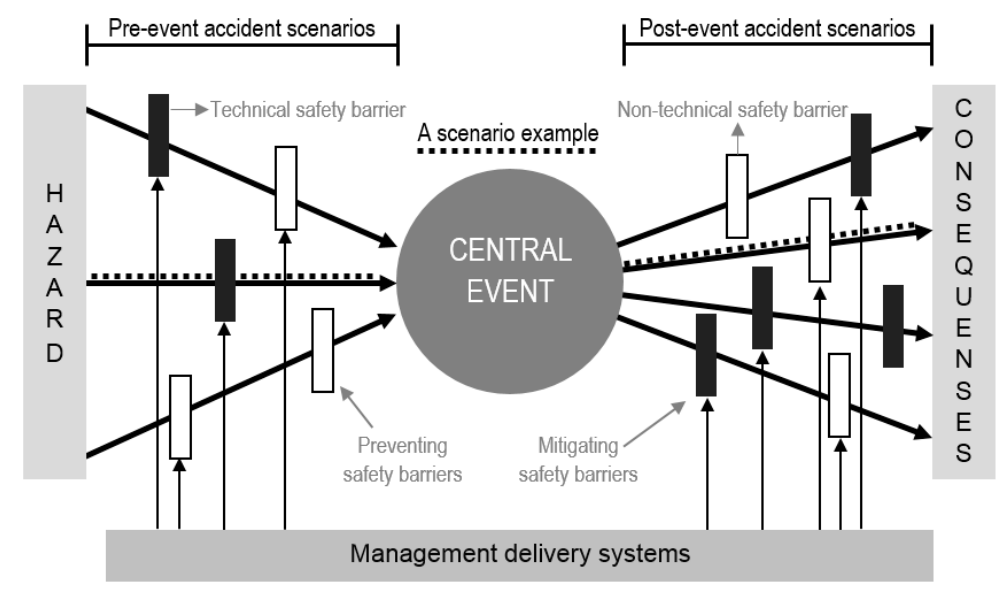

Figure 3. The bow-tie model.

\section{Results}

\subsection{The Outcomes of the Current Accident Analysis in the Plant under Investigation}

At the Belgian plant, pallet mover accidents are being analyzed with the $6 \mathrm{~W}-2 \mathrm{H}$ and why-why techniques. This accident analysis allows us to focus on technical, organizational and human aspects. However, in the accident analysis of the plant, a trend of 'blaming the victim' can be identified. For example, looking at the pallet mover accident as described in the Appendix A, the following aspects can be indicated as important contributors for the accident: The area was very crowded creating a narrow maneuvering space, the load that had to be picked up was not standing in the designated zone and the production pressure was high. The accident analysis shows that the involved operator was personally blamed, as disciplinary measures against the operator were taken by the contractor company.

The countermeasures that are taken based on the results of the accident analysis are also mainly directed towards the operators, such as giving personal warnings and the retraining of pallet mover operators. The observation checklist to evaluate the behavior of operators during the use of pallet movers is often used after an incident occurred, meaning that it is implicitly assumed that the behavior of the operator is one of the root causes of incidents. Organization-oriented countermeasures mainly focus on the adaptation of the working environment to create more maneuvering space and a better overview.

\subsection{Bow-Ties of Accident Processes with Pallet Movers}

Table 1 presents an overview of the left side of the bow-tie: Possible hazards, pre-event accident scenarios, preventing technical and non-technical safety barriers, preventing management delivery systems, and central events of accident processes with pallet movers. Table 2 comprises central events, mitigating technical and non-technical safety barriers, mitigating management delivery systems, post-event accident scenarios, and consequences. 
Tables 1 and 2 were composed based on the findings of the literature study [24-40], information available through Belgian and Dutch national accident databases, the analysis of documents and data available at the Belgian plant regarding pallet movers, and the results of the fieldwork (observations and interviews). 
Table 1. The elements on the left-hand side of the bow-ties of accident processes with pallet movers based on: ${ }^{(1)}$ Literature; ${ }^{(2)}$ Belgian and Dutch National data;

${ }^{(3)}$ Document analysis; ${ }^{(4)}$ Safety notifications in the incident registration system of the Belgian plant; ${ }^{(5)}$ Accident analysis; ${ }^{(6)}$ Fieldwork: Observations and interviews.

\begin{tabular}{|c|c|c|c|}
\hline Hazard & Pre-Event Accident Scenario & $\begin{array}{c}\text { Preventing Technical and Non-Technical Safety Barriers and Management } \\
\text { Delivery Systems }\end{array}$ & Central Event \\
\hline - $\operatorname{Load}^{(1,2,3,4,5,5)}$ & $\begin{array}{l}\text { - Limited sight due to height of load (1,2,3,5,6) } \\
\text { - Load not secured/not well secured (e.g., no cage, not } \\
\text { strapped) (e.g., due to production pressure }{ }^{(1,2,3,4,5,6)} \\
\text { - Load wrongly loaded (e.g., not centered, too highly } \\
\text { loaded, forks under width pallet instead of length, } \\
\text { containers not straight on each other, too heavy) }(2,3,4,5,6)\end{array}$ & 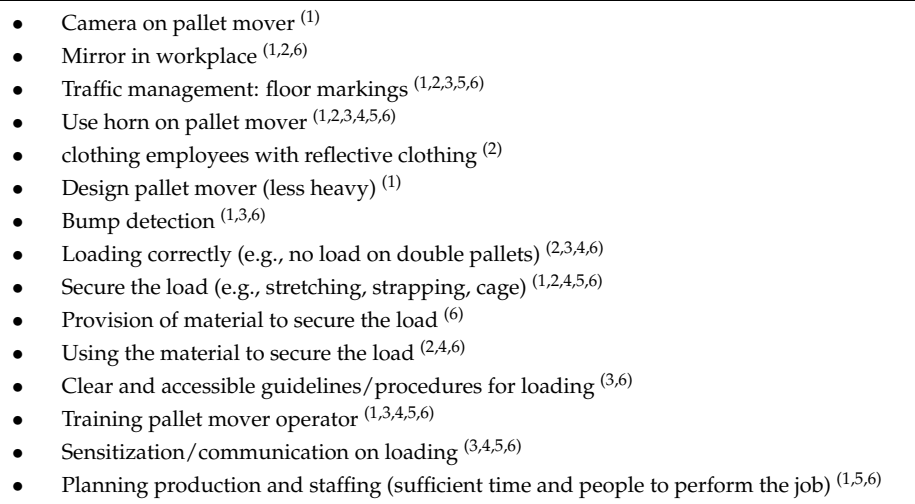 & $\begin{array}{l}\text { - } \quad \text { Unstable load }(1,2,3,4,5,6) \\
\text { - } \quad \text { Loss of pallet mover control }(1,2,3,4,5,6)\end{array}$ \\
\hline $\begin{array}{l}\text { - } \quad \text { Speed pallet mover }{ }^{(1,2,3,4,6)} \\
\text { - }\end{array}$ & $\begin{array}{l}\text { - Driving or accelerating too fast }(1,2,3,4,6) \\
\text { - } \\
\text { - } \\
\text { Due to proding to to take a break faster } \\
\text { Due gross negligence (play behavior, act tough) }\end{array}$ & 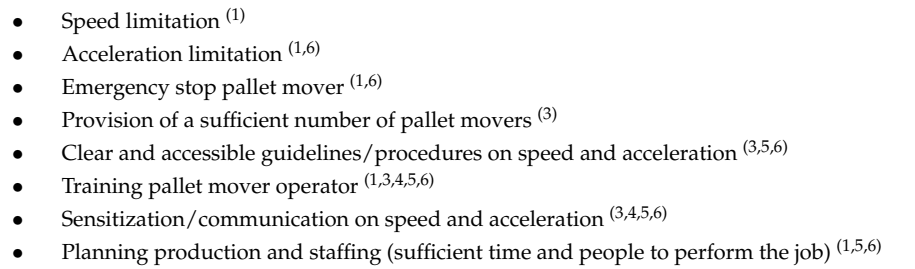 & $\begin{array}{l}\text { - Unstable load }(1,2,3,4,5,6) \\
\text { - Loss of pallet mover control }(1,2,3,4,5,6)\end{array}$ \\
\hline - Design workspace ${ }^{(1,2,3,4,5,6)}$ & 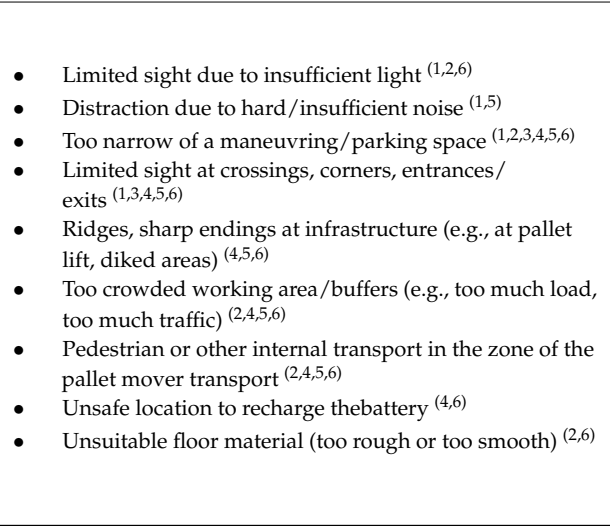 & 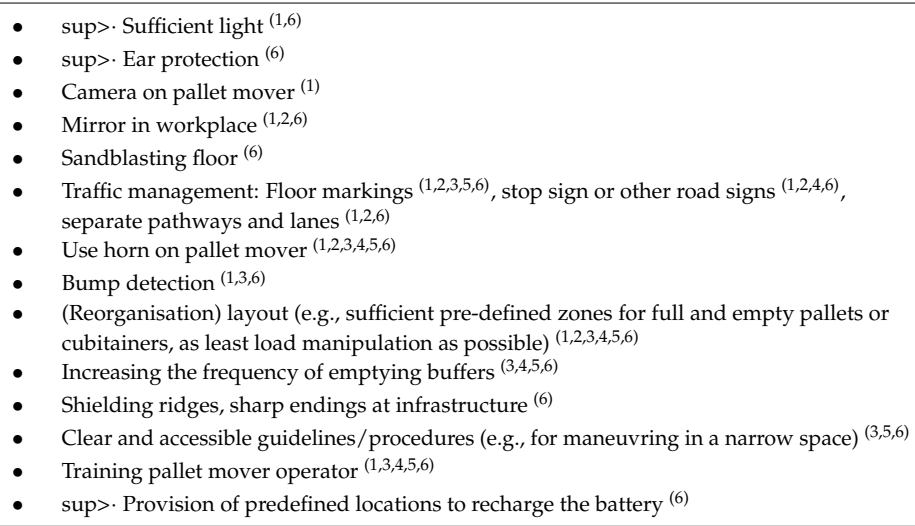 & $\begin{array}{l}\text { - Unstable load }(1,2,3,4,5,6) \\
\text { - Loss of pallet mover control }(1,2,3,4,5,6)\end{array}$ \\
\hline
\end{tabular}




\begin{tabular}{|c|c|c|c|}
\hline Hazard & Pre-Event Accident Scenario & $\begin{array}{c}\text { Preventing Technical and Non-Technical Safety Barriers and Management } \\
\text { Delivery Systems }\end{array}$ & Central Event \\
\hline $\begin{array}{l}\text { - Condition } \\
\text { workspace } \\
(1,2,3,4,5,6)\end{array}$ & $\begin{array}{l}\text { - Floor in bad condition (e.g., holes, loose floor } \\
\text { plates) })^{(1,2,3,4,6)} \\
\text { - Insufficient housekeeping (e.g., loads outside } \\
\text { predefined spaces, pallets not stacked correctly) }(2,3,4,5,6) \\
\text { - Insufficient cleanliness (e.g., wet floor, the products on } \\
\text { the floor) }(2,3,4,5,6) \\
\text { - Incoming rain, humidity of the workspace due to } \\
\text { condensation }(6)\end{array}$ & 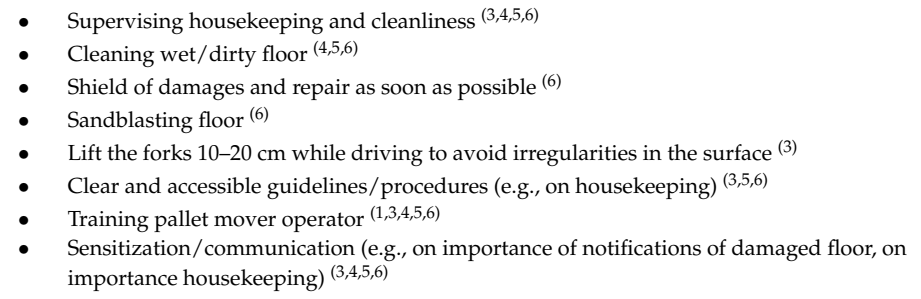 & $\begin{array}{l}\text { - Unstable load }(1,2,3,4,5,6) \\
\text { - Loss of pallet mover control }(1,2,3,4,5,6)\end{array}$ \\
\hline $\begin{array}{l}\text { - Condition material } \\
\text { (equipment and } \\
\text { load) }(1,2,3,4,5,6)\end{array}$ & 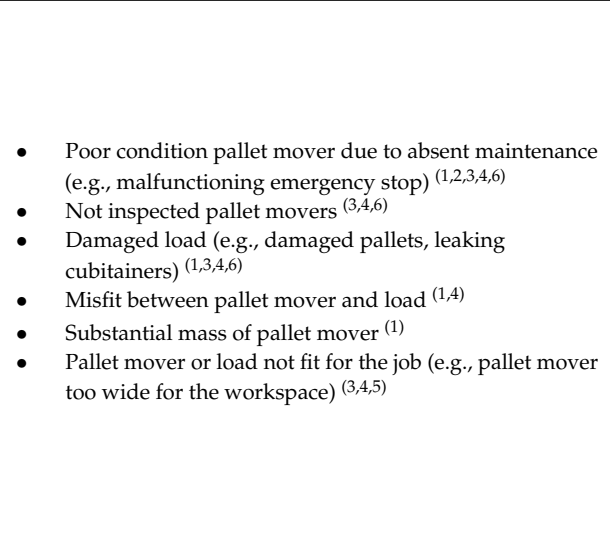 & 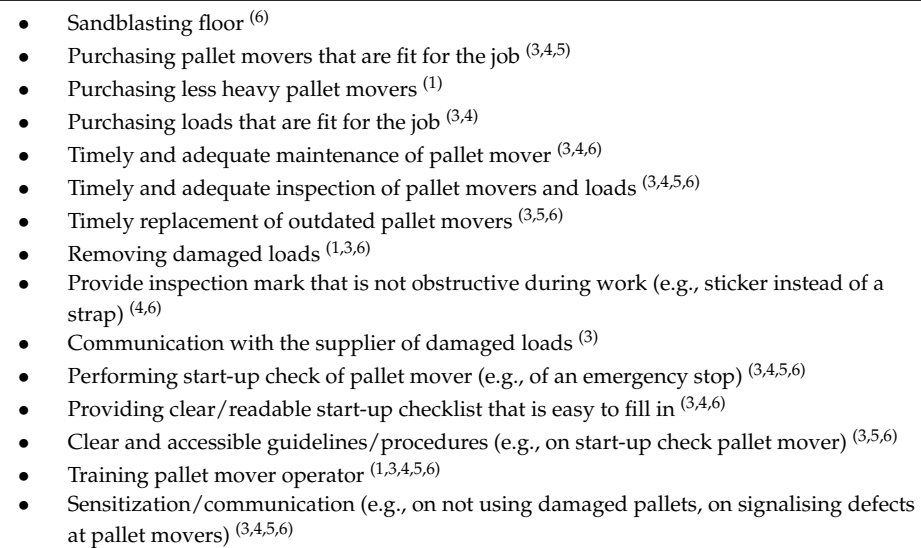 & $\begin{array}{l}\text { - Unstable load }(1,2,3,4,5,6) \\
\text { - } \quad \text { Loss of pallet mover control }(1,2,3,4,5,6) \\
\text { Breakdown pallet mover }(1,2,3,4,5,6)\end{array}$ \\
\hline
\end{tabular}




\begin{tabular}{|c|c|c|c|}
\hline Hazard & Pre-Event Accident Scenario & $\begin{array}{c}\text { Preventing Technical and Non-Technical Safety Barriers and Management } \\
\text { Delivery Systems }\end{array}$ & Central Event \\
\hline $\begin{array}{l}\text { - Operating the pallet } \\
\text { mover }{ }^{(1,2,3,4,5,6)}\end{array}$ & 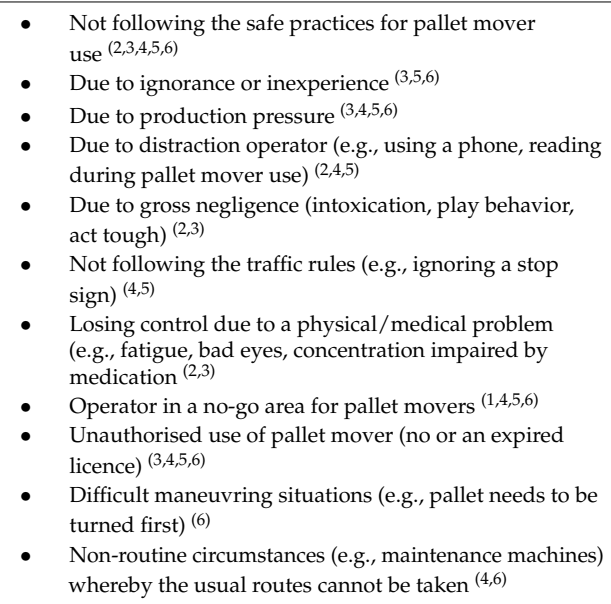 & 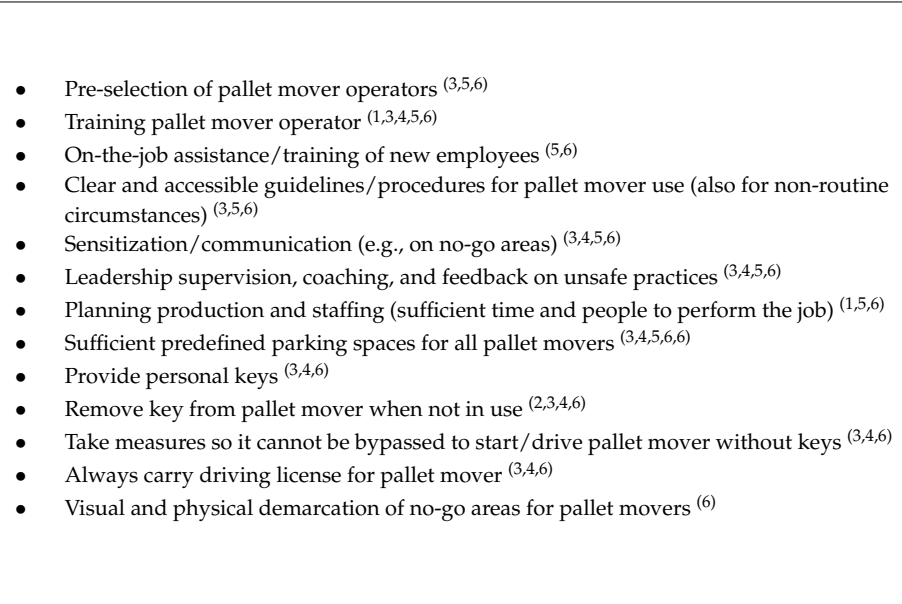 & $\begin{array}{l}\text { - } \quad \text { Unstable load }(1,2,3,4,5,6) \\
\text { - Loss of pallet mover control }(1,2,3,4,5,6)\end{array}$ \\
\hline
\end{tabular}


Table 2. The elements on the right-hand side of the bow-ties of the accident processes with pallet movers based on the ${ }^{(1)}$ Literature; ${ }^{(2)}$ Belgian and Dutch National data; ${ }^{(3)}$ Document analysis; ${ }^{(4)}$ Safety notifications in the incident registration system of the Belgian plant; ${ }^{(5)}$ Accident analysis; ${ }^{(6)}$ Fieldwork: observations and interviews.

\begin{tabular}{|c|c|c|c|}
\hline Central Event & $\begin{array}{c}\text { Mitigating Technical and Non-Technical Safety Barriers and Management } \\
\text { Delivery Systems }\end{array}$ & Post-event Accident Scenario & Consequence \\
\hline - Unstable load $(1,2,3,4,5,6)$ & 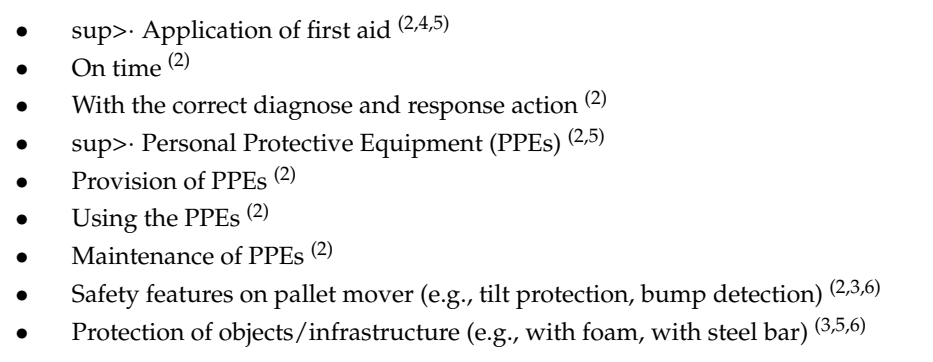 & - Loss of load $(1,2,3,4,5,6)$ & $\begin{array}{ll}\text { - } & \text { Injury }(1,3,4,5,6) \\
\text { - } & \text { Damage }{ }^{(1,3,4,5,6)} \\
\text { - } & \text { Stop production process }(4,5,6)\end{array}$ \\
\hline $\begin{array}{l}\text { - } \quad \begin{array}{l}\text { Loss of control pallet } \\
\text { mover }(1,2,3,4,5,6)\end{array} \\
\text { - } \quad \text { Breakdown pallet mover }(1,2,3,4,5,6)\end{array}$ & 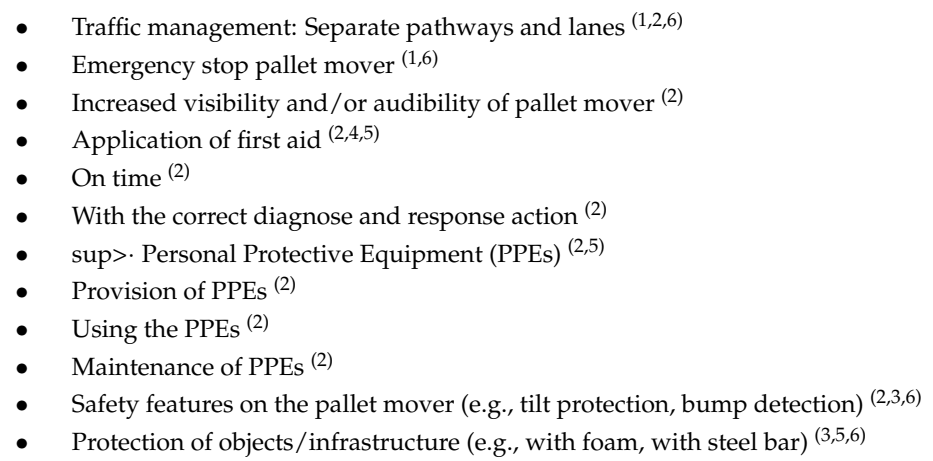 & $\begin{array}{ll}\text { - } & \text { Pallet mover hits } \\
\text { pedestrian/other internal } \\
\text { transport }(1,2,3,4,5,6) \\
\text { - } \\
\text { Pallet mover hits operator pallet } \\
\text { mover }(1,2,3,4,5,6) \\
\text { - } & \begin{array}{l}\text { Pallet mover hits } \\
\text { object/infrastructure }(1,2,3,4,5,6)\end{array}\end{array}$ & $\begin{array}{ll}- & \text { Injury }(1,3,4,5,6) \\
- & \text { Damage }(1,3,4,5,6) \\
- & \text { Economic loss (because of a stop } \\
& \text { of the production process) })^{(4,5,6)}\end{array}$ \\
\hline
\end{tabular}




\section{Assigning Indicators to the Bow-Ties}

Once the bow-ties are composed, they are an excellent point of departure to assign indicators to the technical and non-technical safety barriers and to the management delivery systems in order to control (i.e., prevent or mitigate) the accident scenarios. Indicators can support a company's safety management and provide information on a preferred safety goal.

It is important that the indicators focus on aspects that are applicable to the operating environment. For instance, it could be an improvement to replace all present pallet movers with new, less heavy equipment. However, in the context of the company, it is possible that this is not feasible due to budgetary constraints. Another example is the reorganization of the layout of the floors, which is an important aspect in order to create more maneuvering space. However, in the plant under investigation, installations are integrated into an existing space which was initially not designed for that purpose, leading to space constraints. Additionally, in the past years, several improvements have already been made regarding the layout of the working space and the work floor, and there is, of course, a limitation to the possibilities in creating more maneuvering space. A question arising from this space constraint is whether pallet movers are the best equipment to use at particular spaces in a production facility with limited maneuvering space and if it would not be better to search for an alternative way to transport the material. This is related to the inherent safety of a company [41], which will be discussed at the end of this section.

Besides the applicability of indicators in the company environment, the focus of the indicators can also be chosen based on the presence of management delivery systems. For instance, as can be seen in Tables 1 and 2, certain management delivery systems are present in multiple scenarios. It concerns the following management delivery systems: 'training of pallet mover operators', 'sensitization and communication', 'guidelines and procedures', and 'planning of production and staffing'. Indicators assigned to these management delivery systems can be considered as general indicators, as they are linked to multiple accident scenarios. As an example, the management delivery systems 'training of pallet mover operators' is further elaborated below.

Next to the general indicators, scenario-specific indicators can also be developed. Decisions on what scenarios should be focused on can be based on the plant-specific risks regarding pallet mover use. Two examples of company-specific pre-scenarios will be further elaborated below, being 'narrow maneuvering space' and 'leaking cubitainers'.

\subsection{General Indicators: Training of Pallet Mover Operators}

In Table 3, the possible indicators for the frequently occurring management delivery system 'training of pallet mover operators' have been elaborated. An indicator of the content of the (re)training is proposed, and an indicator of the quality control of the (re)training. Additionally, there are indicators regarding the coverage ratio of the training and the retraining.

Table 3. Possible indicators for the management delivery system 'training of pallet mover operators'.

\begin{tabular}{|c|c|c|}
\hline \multirow{6}{*}{ Sequentiality in follow-up } & \multirow{3}{*}{ Content (re)training } & $\begin{array}{l}\text { Evaluation of the content of the (re)training every two years: Is the } \\
\text { (re)training completely tailored to the needs of the company? } \\
\text { (yes/no)Aspects to take into consideration: }\end{array}$ \\
\hline & & $\begin{array}{l}\text { - Use of examples of specific risks and possible accident } \\
\text { scenarios at the company? E.g., narrow maneuvring spaces, } \\
\text { wet floors, too crowded buffers... }\end{array}$ \\
\hline & & Sufficient rules and guidelines for the target audience? \\
\hline & Quality control (re)training & $\begin{array}{l}\text { Yearly evaluation of the percentage of participants of the } \\
\text { (re)training evaluating the training as positively (i.e., a score of } 7 \text { out } \\
\text { of } 10 \text { or higher) }\end{array}$ \\
\hline & Coverage ratio training & $\begin{array}{l}\text { Monthly evaluation of the percentage of starting pallet mover } \\
\text { operators that are trained for pallet mover use }\end{array}$ \\
\hline & Coverage ratio retraining & $\begin{array}{l}\text { Yearly evaluation of percentage pallet mover operators receiving a } \\
\text { retraining every five years }\end{array}$ \\
\hline
\end{tabular}


It should be noted that a certain sequentiality is present in the follow-up of the indicators. For instance, a high coverage ratio of the (re)training is negligible if the content of the (re)training is not tailored to the needs of the company and if the quality of the (re)training is evaluated as substandard.

\subsection{Scenario-Specific Indicators: Narrow Maneuvering Space}

A specific risk at the plant under investigation is the narrow maneuvering space. Therefore, this scenario was chosen to be further elaborated into scenario-specific indicators. Figure 4 shows the bow-tie of the pre-event accident scenario of a narrow maneuvering space. Only a selection of possible safety barriers and management delivery systems has been included in the bow-tie. Two non-technical safety barriers have been included: 'no pallet mover use at too narrow spaces' and 'correct pallet mover use at narrow spaces'. One technical safety barrier has been included: 'sandblasting floor'. Sandblasting of the transportation routes with pallet movers (Figure 5) leads to a better grip and a shorter breaking distance. The following management delivery systems have been included: 'traffic management' and 'training pallet mover operators'.

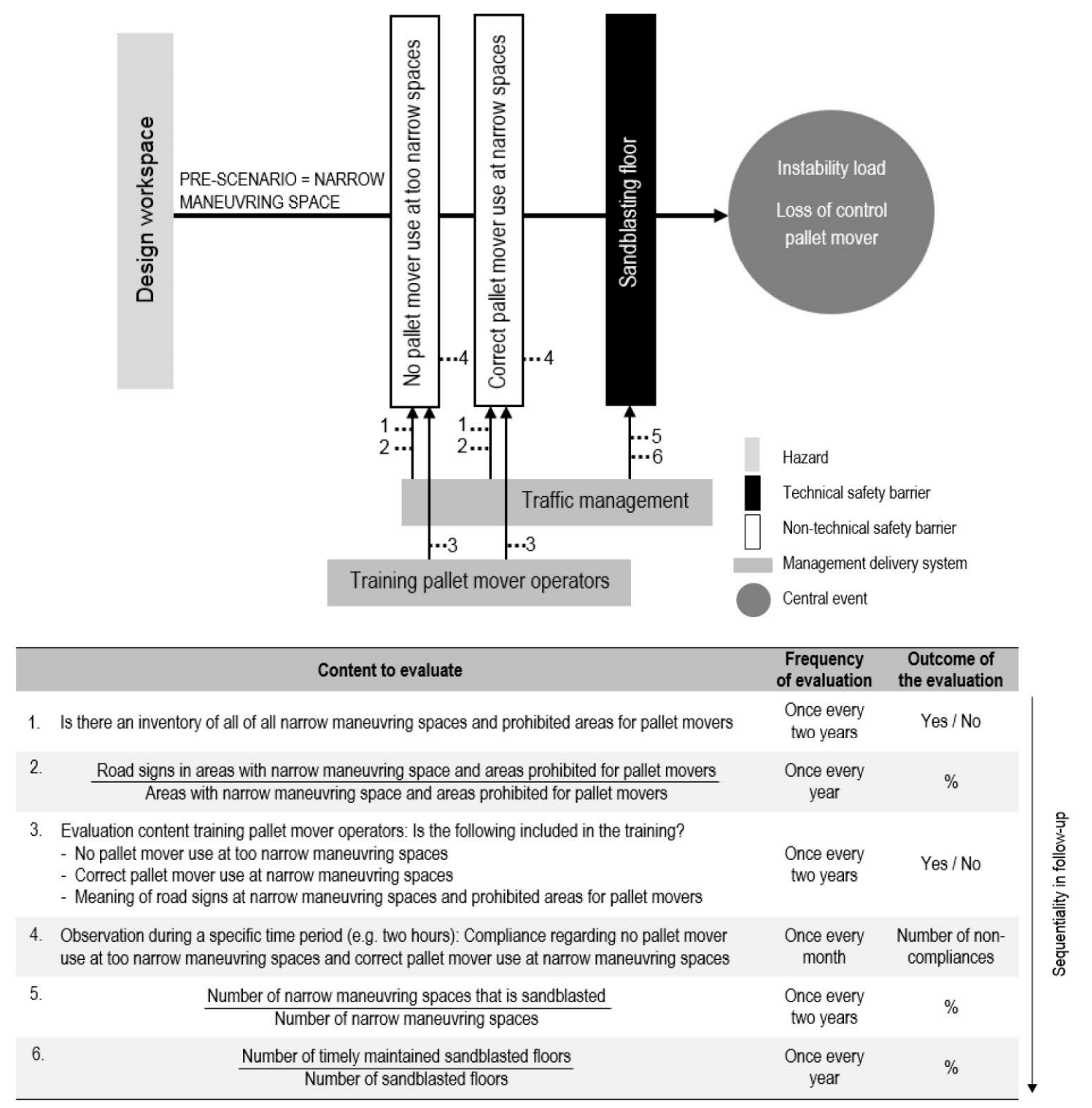

Figure 4. The possible indicators for the pre-scenario of 'narrow maneuvring spaces'. 


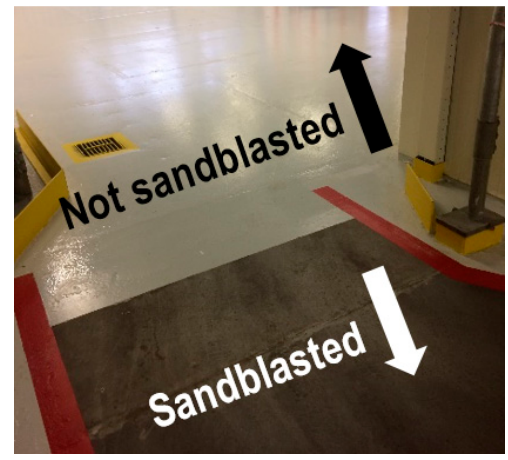

Figure 5. An example of a sandblasted and not sandblasted pallet mover transportation route.

As with the general indicators, a sequentiality is also present in the follow-up of the scenariospecific indicators. For example, when a company does not include correct pallet mover use at narrow maneuvering spaces in the training, it does not make sense to evaluate non-compliances on this topic.

\subsection{Scenario-Specific Indicators: Leaking Cubitainer}

Another specific risk at the plant under investigation is the worn drain valves of cubitainers, leading to spills of liquid content (Figure 6). Products on floors lead to a longer breaking distance and a higher chance of losing control over the pallet mover. Figure 7 presents the bow-tie of the pre-event accident scenario of damaged loads, and more specific leaking cubitainers, complemented with possible indicators for this specific scenario. Again, only a selection of possible safety barriers and management delivery systems has been included in the bow-tie, namely, the non-technical safety barriers 'purchasing cubitainers fit for the job', 'removal of leaking cubitainers', and 'removal of leaked product', the technical safety barrier 'sandblasting floor', and the management delivery systems 'training pallet mover operators' and 'traffic management'.

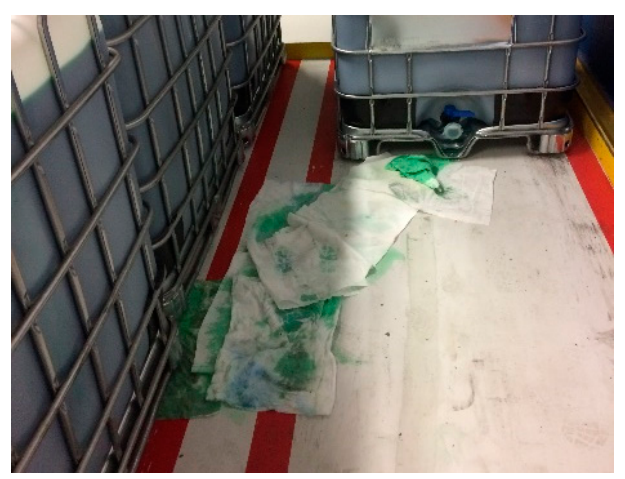

Figure 6. A cubitainer with leaking drain valves leading to a spill of the liquid content. 


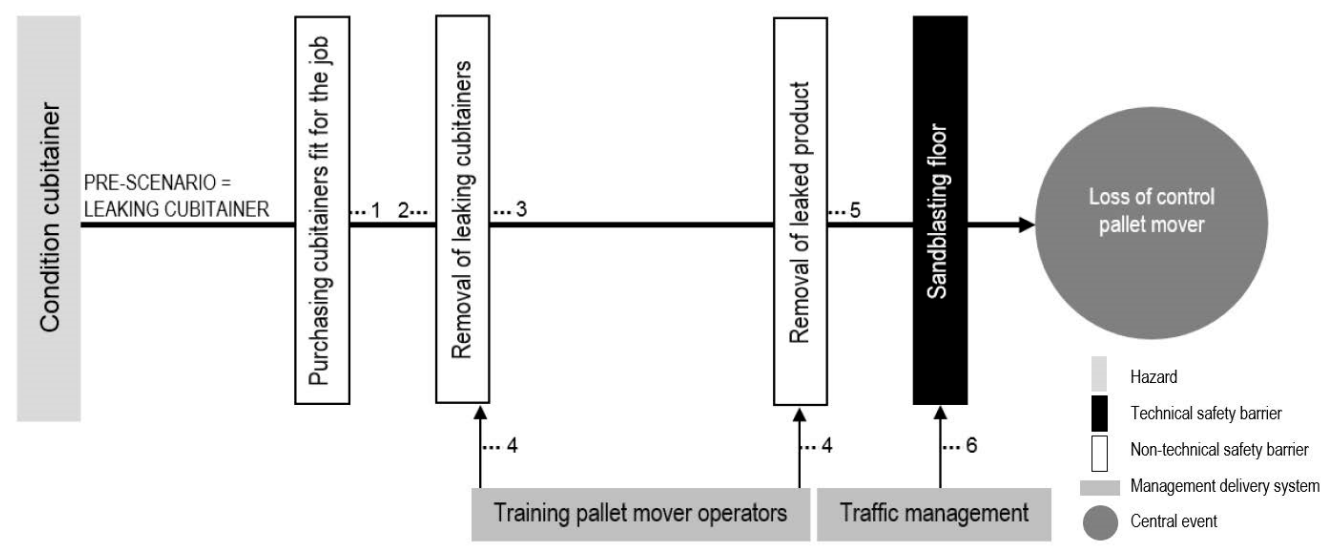

\begin{tabular}{|c|c|c|c|}
\hline & Content to evaluate & $\begin{array}{l}\text { Frequency } \\
\text { of evaluation }\end{array}$ & $\begin{array}{l}\text { Outcome of } \\
\text { the evaluation }\end{array}$ \\
\hline 1. & $\begin{array}{l}\text { Evaluation of the supplier(s) of the cubitainers: } \\
\qquad \frac{\text { Number of newly purchased cubitainers that leak }}{\text { Number of newly purchased cubitainers }}\end{array}$ & $\begin{array}{l}\text { Once every } \\
\text { year }\end{array}$ & $\%$ \\
\hline 2. & $\frac{\text { Number of cubitainers that leak }}{\text { Number of cubitainers }}$ & $\begin{array}{l}\text { Once every } \\
\text { month }\end{array}$ & $\%$ \\
\hline 3. & $\frac{\text { Number of leaking cubitainers that are removed immediately }}{\text { Number of leaking cubitainers }}$ & $\begin{array}{l}\text { Once every } \\
\text { month }\end{array}$ & $\%$ \\
\hline 4. & $\begin{array}{l}\text { Evaluation content training pallet mover operators: Is the following included in the } \\
\text { training? } \\
\text { - Not using leaking cubitainers } \\
\text { - Signalizing leaking cubitainers } \\
\text { - Immediately cleaning leaked product on the floor }\end{array}$ & $\begin{array}{l}\text { Once every } \\
\text { two years }\end{array}$ & Yes / No \\
\hline 5. & $\begin{array}{l}\text { Observation during a specific time period (e.g. two hours): Compliance with } \\
\text { immediately cleaning leaked product on the floor }\end{array}$ & $\begin{array}{l}\text { Once every } \\
\text { month }\end{array}$ & $\begin{array}{l}\text { Number of non- } \\
\text { compliances }\end{array}$ \\
\hline 6. & $\frac{\text { Number of transportation routes with cubitainers that is sandblasted }}{\text { Number of transportation routes with cubitainers }}$ & $\begin{array}{l}\text { Once every } \\
\text { two years }\end{array}$ & $\%$ \\
\hline
\end{tabular}

Figure 7. The possible indicators for the pre-scenario of 'leaking cubitainer'.

\subsection{Evaluation of the Indicators}

Once the indicators have been determined, they have to be evaluated. Based on the specificity of the indicator and the needs of the company, this evaluation can take place on a yearly basis, or if needed with a lower or a higher frequency.

Additionally, after the development of the indicators, targets and limits have to be assigned to every indicator. This means that the company has to decide what is acceptable as a result and what is not. In the example of the coverage ratio of the training, a target could be that $100 \%$ of all pallet mover operators should be trained for pallet mover use. In the example of the number of leaking cubitainers, a target could be that $<5 \%$ of the cubitainers is leaking.

An important aspect is that responsibilities have to be indicated: Who does what and when in order to reach the goals of the indicators. In the example of the (re)training, responsibility has to be indicated for the subscriptions for the (re)training. The same applies to responsibilities to take actions when a target is not achieved.

Based on the elaborated examples, it could seem that a lot of collection and registration is needed for all indicators. However, it should be noted that the given examples and their accompanying indicators are very specific. Once the entire set of indicators has been developed, it will become clear that many of them can be collected and registered under the same heading.

In order to facilitate an adequate monitoring of the indicators, a system should be set up to report and to collect the required data. Such systems are often already (partly) present in a company.

To be complete, something should be said on the necessity of the indicators, which is a reflection that should be made before developing the indicators. After all, it should first be analyzed if the 
processes that are present in the company are as inherently safe as possible [41]. In the given example regarding the narrow maneuvering spaces, whether a pallet mover is the safest equipment to use at these places (and by extension at all places) should be considered. In the example of the leaking cubitainers, whether cubitainers are necessary and if the process cannot be designed in such a way that the transportation of the liquid is minimalized (and by extension that a large amount of manipulation of all loads at the plant is minimalized) should be considered. Kletz's [42] article entitled "what you don't have, can't leak" is a good resume of this matter.

\section{Discussion and Conclusions}

The outcomes deriving from the current accident analysis that is used at the Belgian plant under investigation (6W-2H and why-why technique) does not seem sufficient to take adequate measures in order to prevent accidents with pallet movers. When preventive measures are taken based on accident analyses, several shortcomings can be identified. Firstly, preventive measures based on accident analyzes only focus on accidents that already occurred, leaving all other potential accident scenarios out of scope. A method that includes not only company specific data, but also generic data sources such as the literature and national accident data, generates information on the entire accident process, including aspects that have not (yet) occurred at a specific plant. Additionally, it can be concluded that the recommendations resulting from the current accident analysis that is used at the plant under investigation, are mostly individual-oriented. This is however not an intrinsic problem of the $6 \mathrm{~W}-2 \mathrm{H}$ and why-why technique, as this technique focusses on both technical, organizational as human aspects. Hence, the focus on the human aspects is not a consequence of the technique itself, but of the way the technique is applied.

To address the shortcomings of the current accident analysis, an alternative method-i.e., the bow-tie method-is chosen in order to address pallet mover safety. The bow-tie was chosen for several reasons. Firstly, the bow-ties were composed using a multi-method design. This multi-method design leads to a better comprehensiveness of the entire accident process of pallet mover use and gives a detailed overview of what could possibly go wrong with a pallet mover. In the bow-ties, the possible causes and consequences of potential accidents are identified. Additionally, the bow-tie includes the influence of safety measures (safety barriers and management delivery systems) on the evolution of accident scenarios [43].

Due to the use of a multi-method design to compose the bow-ties, not only company specific data were included, but also generic data sources such as the literature and national accident data. This leads to information on the entire accident process, including aspects that have not (yet) occurred at a specific plant.

Because of the comprehensive character of the bow-tie method, the results are easily transferable to other production facilities where pallet movers are used for internal transport, assuming that the hazards are the same. This means that, if this study was conducted in another production facility with similar hazards and similar a working environment, composition of the bow-ties would have led to a similar outcome as in Tables 1 and 2 (this does not mean that the process of linking indicators to the bow-ties is the same, as this is very company specific). In other words, the bow-tie method leads to a general model that is transferable and applicable in every setting where, in this case, pallet movers are being used. However, the indicators may be different.

Another advantage of the bow-tie method is that it allows us to make a clear distinction between preventing and mitigating safety barriers and management delivery systems.

Seven hazards regarding pallet mover use could be identified based on the composition of the bow-ties: Load, the speed of the pallet mover, acceleration of the pallet mover, the design of the workplace, conditions of the workplace, conditions of materials (load and pallet mover), and operating the pallet mover. Through several identified pre-event accident scenarios, these hazards can lead to different central events: Instability of the load, loss of control over the pallet mover, and a breakdown of the pallet mover. At their turn, these central events can lead through several post-accident scenarios 
to different consequences: Injury, damage, or economic loss. Several technical and non-technical safety barriers and management delivery systems to prevent or mitigate the central event could be linked to the accident scenarios.

The identified safety barriers and management delivery systems mainly focus on organizational aspects, and, to a lesser extent, on the individual behavioral aspects of operators. The pitfall of 'blaming the victim', which is often present in other methods of accident analysis where there is primarily focused on the individual behavior of the operators, is therefore reduced when using the bow-tie method.

Once bow-ties are composed and safety barriers and management delivery systems have been identified, indicators should be developed and monitored consequently. These indicators should be composed based on their applicability in the company, meaning what is possible given a specific company environment. When developing indicators, an important distinction can be made. Firstly, there are general indicators. In the bow-ties, certain management delivery systems can be linked to many of the accident scenarios. When indicators are developed for frequently occurring management delivery systems, these indicators can be considered as general because they are not linked to only one scenario. Secondly, there are scenario-specific indicators. This means that indicators are linked to specific scenarios that require attention in a plant. With both the general and the scenario-specific indicators, a certain sequentiality should be acknowledged in the follow-up of the indicators. For all indicators, it is therefore important to set priorities.

To conclude, indicators are an important result of a bow-tie analysis. When a company reaches a consensus on a set of indicators to be monitored, a unique insight is obtained on the status and development of potential accident scenarios. Management can intervene adequately to ensure a safe production.

Author Contributions: Conceptualization, K.v.N., P.S. and G.R.; Methodology, K.v.N., P.S. and G.R.; Validation, K.v.N., P.S. and G.R.; Formal Analysis, K.v.N and P.S.; Investigation, K.v.N and P.S.; Data Curation, K.v.N., P.S. and G.R.; Writing-Original Draft Preparation, K.v.N.; Writing-Review \& Editing, P.S., G.R., N.P., O.A. and K.P.; Visualization, K.v.N.; Supervision, G.R.; Project Administration, K.v.N.; Funding Acquisition, G.R."

Acknowledgments: The authors would like to thank the company under investigation in this article for their cooperation and for the possibility to conduct this research.

Conflicts of Interest: The authors declare no conflict of interest.

\section{Appendix A}

Table A1. An example of a recordable accident with a pallet mover at the Belgian plant (input based on the $6 \mathrm{~W}-2 \mathrm{H}$ and why-why analysis).

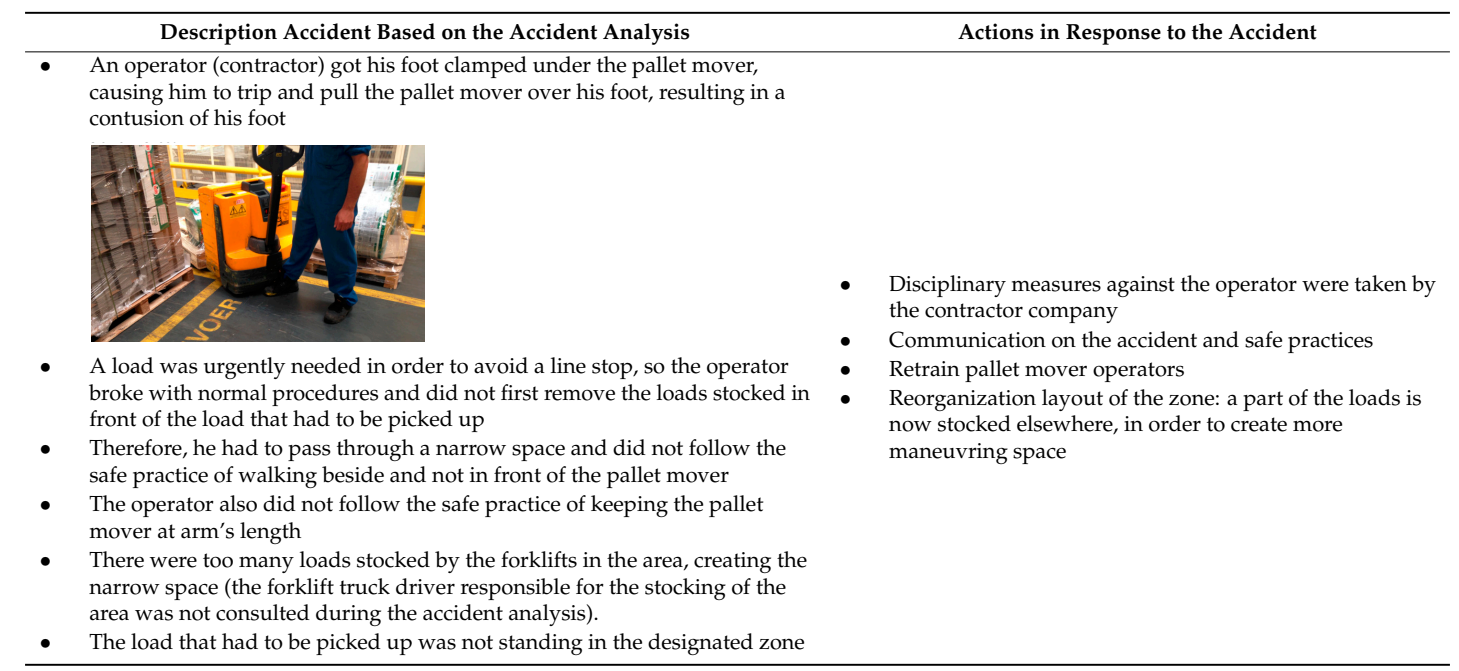




\section{References}

1. Bellamy, L.; Ale, B.; Whiston, J.; Mud, M.; Baksteen, H.; Hale, A.; Papazouglou, L.; Bloemhoff, A.; Damen, M.; Oh, J. The software tool storybuilder and the analysis of horrible stories of occupational accidents. Saf. Sci. 2008, 46, 186-197. [CrossRef]

2. DeBlois, L. Industrial Safety Organization for Executives and Engineer; McGraw-Hill Book Company: New York, NY, USA, 1926.

3. Gibson, J. The contribution of experimental psychology to the formulation of the problem or safety-A letter for basic research. Behavioural Approaches to Accident Research. In Accident Research, Methods and Approaches; Haddon, W., Suchman, E., Klein, D., Eds.; Harper \& Row: New York, NY, USA, 1961.

4. Haddon, W. A note concerning accident theory and research with special reference to motor vehicle accidents. Ann. N. Y. Acad. Sci. 1963, 107, 635-646. [CrossRef] [PubMed]

5. Reason, J. Managing the Risks of Organisational Accidents; Alderschot: Ashgate, UK, 1997.

6. Swuste, P.; Gulijk, C.; van Zwaard, W. Safety metaphors and theories, a review of the occupational safety literature of the US UK and The Netherlands, till the first part of the 20th century. Saf. Sci. 2010, 48, 1000-1018. [CrossRef]

7. Swuste, P.; Gulijk, C.; van Zwaard, W.; Oostendorp, Y. Occupational safety theories, models and metaphors in three decades since World War II, in the United States, Britain, and the Netherlands: A literature review. Saf. Sci. 2014, 62, 16-27. [CrossRef]

8. Swuste, P.; Gulijk, C.; van Zwaard, W.; Lemkowitz, S.; Oostendorp, Y.; Groeneweg, J. Developments in the safety science domain in the fields of general and safety management between 1970-1979, the year of the near disaster on Three Mile Island, a literature review. Saf. Sci. 2016, 86, 10-26. [CrossRef]

9. Lu, L.; Liang, W.; Zhang, L.; Zhang, H.; Lu, Z.; Shan, J. A comprehensive risk evaluation method for natural gas pipelines by combining a risk matrix with a bow-tie model. J. Nat. Gas Sci. Eng. 2015, 25, 124-133. [CrossRef]

10. Swuste, P.; Theunissen, J.; Schmitz, P.; Reniers, G.; Blokland, P. Process safety indicators, a review of literature. J. Loss Prev. Process Ind. 2016, 40, 162-173. [CrossRef]

11. Rasmussen, J. Risk management in a dynamic society: A modelling problem. Saf. Sci. 1997, 27, $183-213$. [CrossRef]

12. Leveson, N. A new accident model for engineering safer systems. Saf. Sci. 2004, 42, 237-270. [CrossRef]

13. Hollnagel, E.; Goteman, O. The functional resonance accident model. Proc. Cognit. Syst. Eng. Process Plant 2004, 2004, 155-161.

14. Jacinto, C.; Silva, C. A semi-quantitative assessment of occupational risks using bow-tie representation. Saf. Sci. 2010, 48, 973-979. [CrossRef]

15. Hale, A.; Ale, B.; Bellamy, L.; Whiston, J.; Mud, M.; Papazoglou, I.; Bloemhof, B.; Post, J.; Oh, J. Best practice in risk assessment: Work accidents. In Proceedings of the European Consumer Safety Association Conference, Edinburgh, UK, 20-21 April 2005.

16. Papazoglou, I.A.; Ale, B.J.M. A logical model for the quantification of occupational risks. Reliab. Eng. Syst. Saf. 2007, 92, 785-803. [CrossRef]

17. Papazoglou, I.A.; Aneziris, O.N.; Bellamy, L.J.; Ale, B.J.M.; Oh, J. Quantitative occupational risk model: Single hazard. Reliab. Eng. Syst. Saf. 2017, 160, 162-173. [CrossRef]

18. Aneziris, O.N.; Papazoglou, I.A.; Baksteen, H.; Mud, M.; Ale, B.J.; Bellamy, L.J.; Hale, A.R.; Bloemhoff, A.; Post, J.; Oh, J. Quantified Risk Assessment for Fall from Heights. Saf. Sci. 2008, 46, 198-220. [CrossRef]

19. Aneziris, O.N.; Papazoglou, I.A.; Mud, M.; Damen, M.; Bellamy, L.J.; Manuel, H.J.; Oh, J. Occupational risk quantification owing to falling objects. Saf. Sci. 2014, 69, 55-70. [CrossRef]

20. Aneziris, O.N.; Papazoglou, I.A.; Konstandinidou, M.; Baksteen, H.; Mud, M.; Damen, M.; Bellamy, L.J.; Oh, J. Quantification of occupational risk owing to contact with moving parts of machines. Saf. Sci. 2013, 51, 382-396. [CrossRef]

21. Aneziris, O.N.; Papazoglou, I.A.; Bellamy, L.J.; Mud, M.; Damen, M.; Manuel, H.J.; Oh, J. Occupational Risk Management for activities performed near vehicles. In Proceedings of the 25th European Safety and Reliability Conference (ESREL 2015), Zurich, Switzerland, 7-10 September 2015. 
22. Aneziris, O.N.; Papazoglou, I.A.; Konstandinidou, M.; Baksteen, H.; Mud, M.; Damen, M.; Kuiper, J.; Bellamy, L.J.; Oh, J. Occupational Risk Management for fires. In Proceedings of the European Safety and Reliability Conference (ESREL 2010), Rhodes, Greece, 5-9 September 2010.

23. Papazoglou, I.A.; Konstandinidou, M.; Aneziris, O.N.; Baksteen, H.; Mud, M.; Damen, M.; Kuiper, J.; Bellamy, L.J.; Oh, J. Occupational Risk Management for release of hazardous substances from closed containments. In Proceedings of the European Safety and Reliability Conference (ESREL 2010), Rhodes, Greece, 5-9 September 2010.

24. Stout, N. Characteristics of work related injuries involving forklift trucks. J. Occup. Accid. 1987, 18, 179-190.

25. Miller, B. Forklift safety by design. Prof. Saf. 1988, 33, 18-21.

26. Lifschultz, B.; Donoghue, E. Deaths due to forklift truck accidents. Forensic Sci. Int. 1994, 65, 121-134. [CrossRef]

27. Larsson, T.; Rechnitzer, G. Forklift trucks analysis of severe and fatal; occupational injuries, critical incidents and priority for prevention. Saf. Sci. 1994, 17, 275-289. [CrossRef]

28. Darcy, C.; Lovell, M.; Metcalfe, J. Injuries from forklift trucks. Injury 1995, 26, 285. [CrossRef]

29. Mack, K.; Haslegrave, C.; Gray, M. Usability of manual handling aids for transporting materials. Appl. Ergon. 1995, 26, 353-364. [CrossRef]

30. Born, C.; Ross, S.; Aron, B.; DeLong, W.; Iannacone, W. Patterns of Injury and Disability Caused by Forklift Trucks. J. Trauma 1996, 40, 636-639. [CrossRef] [PubMed]

31. UK-HSE. Safety of Industrial Lift Trucks; HMSO: Norwich, UK, 2003.

32. UK-HSE. Warehousing and Storage Keep It Safe; Health and Safety Executive INDG 412; Health and Safety Executive: Bootle, UK, 2011.

33. UK-HSE. Pallet Safety; Guidance note PM15; Health and Safety Executive: Bootle, UK, 2014.

34. Harris, G.; DeRosia, J. Occupant Protection and Standup Forklift (Lift Truck) Dynamics. In Proceedings of the 2003 ASME International Mechanical Engineering Congress (IMEC'03), Washington, DC, USA, 15-21 November 2003.

35. Larsson, T.; Lambeth, J.; Wilde, M.; Tully, G.; Askew, H.; Skinner, W.; Carter, B.; Martin, T.; Kenningham, L. Industrial forklift trucks, dynamic stability and the design of safe logistics. Saf. Sci. Monit. 2003, 7, 1-14.

36. Horberry, T.; Larsson, T.; Johnston, I.; Lambert, J. Forklift safety traffic engineering and intelligent transport systems: A case study. Appl. Ergon. 2004, 35, 575-581. [CrossRef] [PubMed]

37. St-Vincent, M.; Denis, D.; Imbeau, D.; Laberge, M. Work factors affecting manual materials handling in a warehouse superstore. Int. J. Ind. Ergon. 2005, 35, 33-46. [CrossRef]

38. Berry, T. An analysis of pallet truck incidents. In Proceedings of the ASME 2008 International Mechanical Engineering Congress and Exposition, Boston, MA, USA, 31 October-6 November 2008.

39. Sanders, D. Controlling the direction of walkie type forklifts and pallet jacks on sloping ground. Assem. Autom. 2008, 28, 317-324. [CrossRef]

40. Kleinert, S.; Overmeyer, L. Integration of 3D camera systems on forklift trucks. Logist. J. 2013, 1-7. [CrossRef]

41. Kletz, T. Plant Design for Safety—A User-Friendly Approach; Hemisphere: New York, NY, USA, 1991.

42. Kletz, T. What You Don't Have, Can't Leak. Chem. Ind. 1978, 6, $287-292$.

43. De Dianous, V.; Fievez, C. Aramis project: A more explicit demonstration of risk control through the use of bow-tie diagrams and the evaluation of safety barrier performance. J. Hazard. Mater. 2006, 130, 220-233. [CrossRef] [PubMed]

(C) 2018 by the authors. Licensee MDPI, Basel, Switzerland. This article is an open access article distributed under the terms and conditions of the Creative Commons Attribution (CC BY) license (http://creativecommons.org/licenses/by/4.0/). 